\title{
Bone-Like Mineral Nucleating Peptide Nanofibers Induce Differentiation of Human Mesenchymal Stem Cells into Mature Osteoblasts
}

\author{
Hakan Ceylan, ${ }^{\dagger}$ Samet Kocabey, ${ }^{\dagger}$ Hilal Unal Gulsuner, ${ }^{\dagger}$ Ozlem S. Balcik, ${ }^{\ddagger}$ Mustafa O. Guler, ${ }^{*}{ }^{\dagger}$ \\ and Ayse B. Tekinay* ${ }^{\dagger} \dagger$ \\ ${ }^{\dagger}$ Institute of Materials Science and Nanotechnology, National Nanotechnology Research Center (UNAM), Bilkent University, \\ Ankara, 06800, Turkey \\ ${ }^{\ddagger}$ Department of Hematology, School of Medicine Hospital, Turgut Ozal University, Ankara, 06510, Turkey
}

Supporting Information

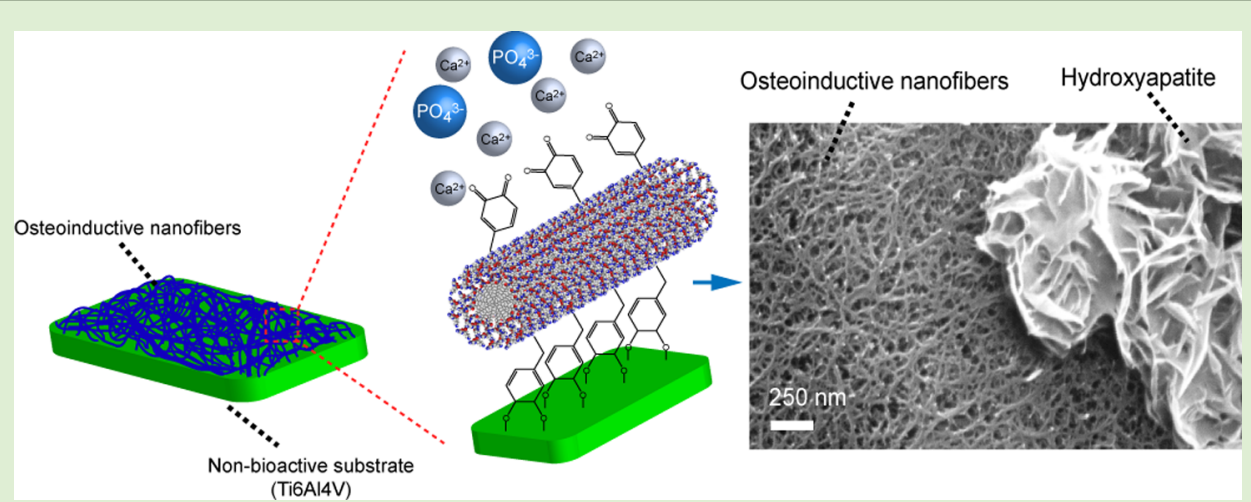

ABSTRACT: A bone implant should integrate to the tissue through a bone-like mineralized interface, which requires increased osteoblast activity at the implant-tissue boundary. Modification of the implant surface with synthetic bioinstructive cues facilitates on-site differentiation of progenitor stem cells to functional mature osteoblasts and results in subsequent mineralization. Inspired by the bioactive domains of the bone extracellular matrix proteins and the mussel adhesive proteins, we synthesized peptide nanofibers to promote bone-like mineralization on the implant surface. Nanofibers functionalized with osteoinductive collagen I derived Asp-Gly-Glu-Ala (DGEA) peptide sequence provide an advantage in initial adhesion, spreading, and early commitment to osteogenic differentiation for mesenchymal stem cells (hMSCs). In this study, we demonstrated that this early osteogenic commitment, however, does not necessarily guarantee a priority for maturation into functional osteoblasts. Similar to natural biological cascades, early commitment should be further supported with additional signals to provide a longterm effect on differentiation. Here, we showed that peptide nanofibers functionalized with Glu-Glu-Glu (EEE) sequence enhanced mineralization abilities due to osteoinductive properties for late-stage differentiation of hMSCs. Mussel-inspired functionalization not only enables robust immobilization on metal surfaces, but also improves bone-like mineralization under physiologically simulated conditions. The multifunctional osteoinductive peptide nanofiber biointerfaces presented here facilitate osseointegration for long-term clinical stability.

\section{INTRODUCTION}

Understanding and controlling the complex interactions at the cell-material interface is important for developing more efficient treatment strategies in regenerative medicine. These cell-material interactions are especially important at the site of contact between the implants and the tissues. Therapeutic success of bone implants relies on efficient tissue integration of the implant, which is governed by formation of a tight, bonelike mineralized layer at the bone-implant interface. ${ }^{1}$ Mineralization process is also under competitive pressure of fibrotic tissue development, which leads to softening of the surrounding bone tissue and, hence, failure of the implant. ${ }^{2-6}$ Particularly in patients with impaired osteoblastogenesis, such as osteoporosis, the mineralization process takes a longer time and failure of the implant is more probable. ${ }^{7}$ Thus, adequate osteoblast activity is necessary for rapid mineralization at the site of implantation.

Mature osteoblasts operate as the functional bone-forming cells by laying down mineralizable bone matrix called osteoid. The hMSCs are the ultimate progenitors of osteoblasts in the adult bone. ${ }^{8}$ In the course of osteogenic differentiation, hMSCs follow a hierarchical pathway within the osteoblast lineage. An

Received: February 17, 2014

Revised: $\quad$ May 28, 2014

Published: May 30, 2014 

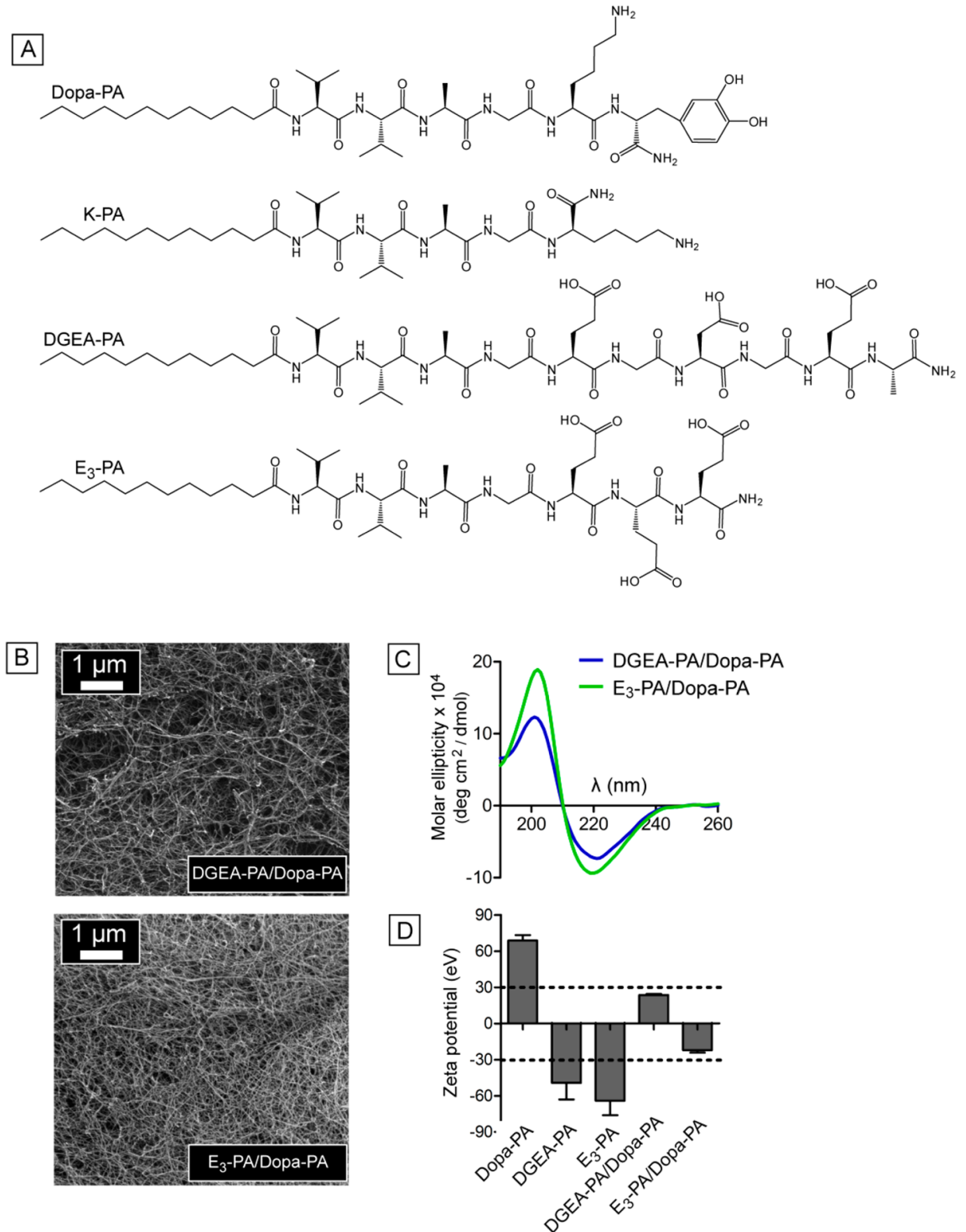

Figure 1. Self-assembly of PAs into multifunctional osteoinductive nanofibers. (A) Design and chemical representation of the building blocks: Lauryl-VVAGKDopa-Am (Dopa-PA), Lauryl-VVAGK-Am (K-PA), Lauryl-VVAGEGDGEA-Am (DGEA-PA), Lauryl-VVAGEEE-Am (E 3 -PA). (B) SEM micrographs of DGEA-PA/Dopa-PA and $\mathrm{E}_{3}$-PA/Dopa-PA nanofibrous matrices formed at $\mathrm{pH}$ 7.4. (C) Circular dichroism spectra of the nanofibers undergoing $\beta$-sheet-like structural organization. (D) Zeta potentials of individual PAs and self-assembled nanofibers, revealing that the charge-screening drives the self-assembly process.

initial osteogenic commitment followed by a maturation step is regulated by a complex set of signaling factors, including intracellular, intercellular, and extracellular interactions, ending with mature osteoblasts. Because of the complexity of the biological processes, synthetic systems with a single function can fail to properly orchestrate this mechanism. In order to overcome this problem, bioinstructive molecules can be used in a multifunctional fashion for inducing maturation after initial differentiation, which is important for providing progenitor cells with clinically relevant competitive advantage.

Recent studies have shown that modifying surfaces with short synthetic peptides derived from bone extracellular matrix proteins can promote survival and differentiation of osteoprogenitor cells with varying potency, including multipotent hMSCs and unipotent preosteoblasts. For example, the Asp-
Gly-Glu-Ala (DGEA) peptide sequence derived from collagen type I can induce osteogenic differentiation of hMSCs and mouse preosteoblast MC3T3 cells via binding to integrin receptor $\alpha 2 \beta 1 .^{10-16} \alpha 2 \beta 1$ is not only critical in the differentiation process, but also in adhesion, spreading, migration, and survival of hMSCs. ${ }^{17}$ On the other hand, Arg-Gly-Asp (RGD) peptide sequence of fibronectin interacts with integrin $\alpha 5 \beta 1$. Blocking integrin $\alpha 5 \beta 1$ reduces adhesion and proliferation despite having any impact on osteogenic differentiation. ${ }^{18}$

In addition to receptor binding epitopes, the regulatory role of the acidic residues in nucleation and growth of hydroxyapatite crystals require special attention since reconstitution of a synthetic process that can stimulate precipitation of carbonated biological apatite on the implanted material would be a useful platform for promoting adhesion, survival, 
and osteogenic differentiation of the progenitor cells. ${ }^{3,19,20}$ Acidic residues in noncollagenous bone matrix proteins, such as bone sialoprotein, osteopontin, and osteocalcin, also exhibit appealing behavior due to their high hydroxyapatite affinity. ${ }^{21}$ It has been shown that, depending on the geometry and porosity, hydroxyapatite (HAp) grafts exhibit osteoinductivity in addition to its osteoconductive properties. This had been attributed to its ability to entrap and concentrate circulating bone morphogenetic proteins (BMPs).,22 Moreover, by comparing osteoinductivity of porous hydroxyapatite with BMP-2, Lin et al. showed that mouse mesenchymal stem cell lines underwent osteogenic differentiation and the osteoinductivity of hydroxyapatite was found to be higher than of BMP-2 itself. $^{23}$ Very recently, Shih et al. proposed that calcium phosphate matrices can induce osteogenic differentiation of mesenchymal stem cells through phosphate-ATP-adenosine metabolic signaling. ${ }^{20}$

Supramolecular assemblies of biofunctional peptides provide well-defined molecular composition and architecture allowing high epitope density with optimal receptor binding geometry. ${ }^{10,24,25}$ Chemical simplicity of the building blocks allows robust exploitation of the bioactive ligands in therapeutic applications. ${ }^{13,24,26-30}$ Peptide amphiphiles (PAs) is a class of self-assembling peptides containing an alkyl tail attached to the peptide part. ${ }^{31}$ Because of the design flexibility, PA nanofibers can display bioinstructive ligands in a multivalent fashion to support adhesion, proliferation, and differentiation of various cell types, including bone, cartilage, endothelial, and nerve cells, as well as their progenitors. ${ }^{32-35}$

In the present study, we demonstrated multifunctional osteoinductive nanofibers that induce differentiation of hMSCs into mature osteoblast. PA molecules that selfassembles into these nanofibers, were synthesized inspired by the bioactive sequences of collagen type I (DGEA), noncollagenous matrix proteins (EEE), and the mussel-adhesive proteins (3,4-dihydroxy-L-phenyl alanine, or Dopa; Figure 1A). Dopa was used to provide immobilization of osteoinductive cues on biomaterial surface, since immobilization is a major drawback, which significantly limits the performance of the available surface modification technologies. Water molecules, dissolved ions, and polyionic biomolecules in the biological environment compete with the implant surface and displace the immobilized molecules. ${ }^{36}$ This challenge has been recently addressed by our group and others by exploiting musselinspired Dopa-mediated surface adhesion strategy. ${ }^{26,37-39}$ Under physiological conditions, these three bioactive PAs self-assembled into hybrid nanofibers, which were then applied as implant coatings on medical grade titanium substrate. We investigated the surface stability and osteoinductivity of these coatings. In vivo biointegration of these nanofibers was predicted by their ability of facilitating mineralization under biologically simulated conditions. Osteoinductivity of these artificial microenvironments was identified in detail by investigating cell-matrix interactions at the molecular level.

\section{MATERIALS AND METHODS}

Synthesis and Characterization of Peptide Amphiphiles. Lauryl-VVAGKDopa-Am (Dopa-PA), Lauryl-VVAGK-Am (K-PA), Lauryl-VVAGEGDGEA-Am (DGEA-PA), and Lauryl-VVAGEEE-Am $\left(\mathrm{E}_{3}-\mathrm{PA}\right)$ were synthesized using Fmoc solid phase peptide synthesis (Table S1). Fmoc protection group on the $\mathrm{N}^{\alpha}$-amino group of the peptide was removed by $20 \%$ piperidine/dimethylformamide at each coupling step. Rink amide MBHA resin (Novabiochem) was used as the solid support. Carboxylate group activation of $2 \mathrm{~mol}$ equivalents (equiv) of amino acids was achieved by 1.95 mol equiv of $N, N, N^{\prime}, N^{\prime}$ tetramethyl-O-(1H-benzotriazole-1-yl) uranium hexafluorophosphate (HBTU) and $3 \mathrm{~mol}$ equiv of diisopropylethylamine (DIEA) for $1 \mathrm{~mol}$ equiv of $\mathrm{N}^{\alpha}$-amino sites attached on the resin. Coupling time at each step was limited to $2 \mathrm{~h}$. For the removal of the protecting groups following the last coupling step, a cleavage cocktail containing $95 \%$ trifluoroacetic acid (TFA), $2.5 \%$ water, and $2.5 \%$ triisopropylsilane was used. Excess TFA was partly removed by rotary evaporation, followed by precipitation in diethyl ether overnight. The precipitate was collected and dissolved in ultrapure water. This solution was frozen at $-80{ }^{\circ} \mathrm{C}$, followed by freeze-drying for 1 week. Residual TFA was removed from PAs with overall positive charge by dissolving the whole batch in dilute $\mathrm{HCl}$ solution with a subsequent dialysis procedure using cellulose ester dialysis membrane with molecular-weight-cutoff of 100-500 Da. For PAs with overall negative charge, a reverse-phase preparative HPLC purification was employed. Following the TFA removal procedure, PAs were once more freeze-dried, and their purity was assessed using Agilent 6530 quadrupole time-of-flight (Q-TOF) mass spectrometry with electrospray ionization (ESI) source equipped with a reverse-phase analytical HPLC (Figure S1).

Formation of Self-Assembled Peptide Nanofibers. Aqueous solutions of all $\mathrm{PAs}$ were prepared at $\mathrm{pH} 7.4$ using diluted $\mathrm{HCl}$ or $\mathrm{NaOH}$. Self-assembly into hydrogels was rapid enough to allow monitoring by eye within a few minutes in the range of 1-10 mM monomer concentrations. The resulting nanonetwork was investigated using scanning electron microscopy (SEM). Following $10 \mathrm{~min}$ of gelation on conductive stainless steel surfaces, hydrogels (formed by $10 \mathrm{mM}$ monomer concentration) were dehydrated in gradually increasing concentrations of ethanol/water solutions. Dehydrated hydrogels were dried using a Tourismis Autosamdri-815B critical point drier to preserve the network structure. The dried samples were coated with $3 \mathrm{~nm} \mathrm{Au} / \mathrm{Pd}$ and visualized under high vacuum with a FEI Quanta 200 FEG SEM equipped with an ETD detector. To investigate the secondary structure of PA nanofibers, circular dichroism (CD) (Jasco J-815) was used. The $5 \times 10^{-5} \mathrm{M}$ DGEA-PA (or $\mathrm{E}_{3}$-PA) was mixed with $5 \times 10^{-5} \mathrm{M}$ Dopa-PA (or K-PA) at 1:3 volume ratios. After $5 \mathrm{~min}$, spectrometric measurement was acquired at room temperature from 260 to $190 \mathrm{~nm}$ with $0.1 \mathrm{~nm}$ data interval and $500 \mathrm{~nm} / \mathrm{min}$ scanning speed. The results were converted to and represented as the molar ellipticity. Zeta potential measurements were performed with a Malvern Zeta-ZS Zetasizer at the same monomer concentrations used in $\mathrm{CD}$.

Stability of Peptide Nanonetworks on Titanium Substrate. The $100 \mu \mathrm{m}$ thick plain medical grade Ti6Al4V (Good Fellow Inc.) substrates were cut into small pieces, followed by ultrasonic cleaning sequentially in acetone, ethanol, and water for $1 \mathrm{~h}$ in each. Samples were then dried under vacuum at $50{ }^{\circ} \mathrm{C}$ for at least $6 \mathrm{~h}$. DGEA-PA/ Dopa-PA, E ${ }_{3}-\mathrm{PA} / \mathrm{Dopa}-\mathrm{PA}$, DGEA-PA/K-PA, and $\mathrm{E}_{3}$-PA/K-PA coatings were formed in situ on Ti6Al4V surfaces. A total of $25 \mu \mathrm{L}$ of 1 mM DGEA-PA (or $\mathrm{E}_{3}-\mathrm{PA}$ ) solutions was mixed with $75 \mu \mathrm{L}$ of $1 \mathrm{mM}$ Dopa-PA (or K-PA) on per square centimeter of Ti6Al4V. The functional epitope concentrations on all nanofiber compositions were equal as shown in Table 1. The mixtures were then slowly dried in a

Table 1. Osteoinductive PA Nanofiber Compositions Forming Bone-Mimetic Cellular Microenvironments

$\begin{array}{lc}\text { nanofiber composition } & \text { monomeric stoichiometry }^{a} \\ \text { DGEA-PA/Dopa-PA } & 1: 3 \\ \text { E }_{3} \text {-PA/Dopa-PA } & 1: 3 \\ \text { HAp (DGEA-PA/Dopa-PA) } & b \\ \text { HAp (E-PA/Dopa-PA) } & { }^{b} \\ \text { DGEA-PA/K-PA } & 1: 3 \\ \text { E }_{3} \text {-PA/K-PA } & 1: 3 \\ \end{array}$

${ }^{a}$ Determined by the molar mixing ratio of the participating PAs. ${ }^{b}$ Immersed in simulated body fluid for hydroxyapatite (HAp) mineralization. 
humidified chamber at $37^{\circ} \mathrm{C}$ for $48 \mathrm{~h}$. K-PA served as the control of Dopa-PA. After drying, the coatings were washed in $10 \times$ PBS for 2 days followed by washing in $10 \mathrm{wt} \%$ SDS for $1 \mathrm{~h}$, all steps accompanied by vigorous shaking. To enhance visibility, the residual nanofibers were then stained with coomassie brilliant blue at room temperature for $1 \mathrm{~h}$, followed by a destaining solution containing water/methanol/acetic acid in a ratio of 50:40:10 for $3 \mathrm{~h}$. To quantify the residual amount, the digital images were used to determine relative spot densities. The densities were normalized to that of $\mathrm{E}_{3}-\mathrm{PA} / \mathrm{K}-\mathrm{PA}$. Each bar represents the average of at least six measurements. A Thermo Scientific X-ray photoelectron spectrometer (XPS) with Al $\mathrm{K} \alpha$ microfocused monochromatic $\mathrm{X}$-ray source was utilized at ultrahigh vacuum $\left(\sim 10^{-9}\right.$ Torr $)$. For XPS, the same sample preparation technique was employed as used in coomassie staining except that SDS washing step lasted $3 \mathrm{~h}$. The spectra were acquired from at least three random locations on each substrate.

Mineralization of Peptide Nanonetworks in Simulated Body Fluid. Titanium substrates coated with peptide nanofibers were prepared as described above. The $1.5 \times$ simulated body fluid (SBF) was prepared at $\mathrm{pH} 7.4$ containing the following ion concentrations: $\mathrm{Na}^{+}$ $213.0 \mathrm{mM}, \mathrm{K}^{+} 7.5 \mathrm{mM}, \mathrm{Mg}^{2+} 2.3 \mathrm{mM}, \mathrm{Ca}^{2+} 3.8 \mathrm{mM}, \mathrm{Cl}^{-} 221.7 \mathrm{mM}$, $\mathrm{HCO}_{3}{ }^{-} 6.3 \mathrm{mM}, \mathrm{HPO}_{4}{ }^{3-} 1.5 \mathrm{mM}, \mathrm{SO}_{4}{ }^{2-} 0.8 \mathrm{mM}$. Prior to immersing in SBF for mineralization, substrates were first washed with SBF to remove any residual particulates. Substrates were then immersed in 5 $\mathrm{mL} \mathrm{SBF}$ per $\mathrm{cm}^{2}$ peptide substrate. Unless otherwise is indicated, the incubation period was set to 3 days at $37^{\circ} \mathrm{C}$ and $\mathrm{pH}$ 7.4. For samples to be used in in vitro assays, the substrates were washed with water and PBS prior to cell seeding. For SEM imaging, samples were dehydrated in ethanol/water gradient. Then, samples were dried in critical point drier as explained in Materials and Methods. For the chemical analysis of the mineral, energy dispersive X-ray spectrometer (EDS), selected area electron diffraction (SAED; both coupled to FEI Tecnai G2 F30 TEM), X-ray diffraction (PANalytical X'Pert Powder), and Raman spectrum (Witec) were employed. Minerals were investigated on day 3 , following a thorough washing with deionized water and subsequent air drying.

Human Mesenchymal Stem Cell Culturing. hMSCs were isolated from the bone marrow of a 31 years old healthy female donor (wt, $80 \mathrm{~kg}$; ht, $163 \mathrm{~cm}$ ). Ethical committee approval was obtained from Turgut Ozal University School of Medicine. We adopted a previously published protocol for isolation of spindle-like colony-forming hMSCs, which exhibit culture plate adherence. ${ }^{40}$ Isolated hMSCs were verified using four positive (CD44, CD90, CD105, integrin $\beta 1$ ) and one negative (CD45) surface marker proteins, which were obtained from Abcam (Figure S8). hMSCs were used in passage numbers between 3 and 7. Cells were maintained in $225 \mathrm{~cm}^{2}$ flasks in Dulbecco's Modified Eagle's Medium (DMEM) containing 20\% fetal bovine serum and 1\% penicillin/streptomycin. Cells were cultivated at standard humidified incubators with constant $5 \% \mathrm{CO}_{2}$ at $37{ }^{\circ} \mathrm{C}$. Detachment of cells was done using trypsin/EDTA chemistry at about $75 \%$ confluency. At each passage, cell seeding density was determined to be $2 \times 10^{3} \mathrm{cells} \mathrm{cm}^{-1}$.

Preparation of Surfaces for In Vitro Assays. Titanium substrates coated with peptide nanofibers were prepared, as described above. In order to remove any residual particulates, coated substrates were washed with PBS prior to cell seeding. Sterilization was achieved via UV irradiation for $2 \mathrm{~h}$.

Cell Adhesion, Spreading and Locomotion. Prior to seeding, hMSCs were incubated with serum-free DMEM supplemented with 3 wt $\%$ albumin (bovine serum) and $0.05 \mathrm{wt} \%$ cyclohexamide for $2 \mathrm{~h}$. Following preincubation, cells were detached by brief trypsinization at room temperature $(\sim 30 \mathrm{~s})$ in order not to chop off the cell surface receptors. Cell seeding density onto the coatings was $3 \times 10^{4}$ cells $\mathrm{cm}^{-1}$. After $2 \mathrm{~h} 15 \mathrm{~min}$, cells were gently washed with PBS on a rotatory shaker. To visualize cells, actin filaments were stained using TRITC-Phalloidin (Sigma-Aldrich). For this, specimens were fixed with $3.7 \mathrm{wt} \%$ formaldehyde followed by permeation with $0.1 \mathrm{vol} \%$ Triton-X. For counter-staining, cell nuclei were stained with TO-PRO3 iodide (Molecular Probes). Adhesion and spreading were quantified based on the images of adhered cells acquired in randomized areas at each substrate. At least five random images were taken from a single replica at $10 \times$ magnification using a fluorescent microscope. For each independent assay, at least four technical replicas were included. Cellular locomotion was assessed based on the average displacement of hMSCs on peptide nanofibers in between a defined time period. hMSCs were seeded at a density of $1 \times 10^{3}$ cells $\mathrm{cm}^{-1}$, with the aim of minimizing intercellular interactions to elucidate the impact of nanofibers on the movement. The consecutive images were acquired using a confocal microscope (Zeiss LSM 510) at every $30 \mathrm{~min}$ for $6 \mathrm{~h}$ in total.

Cell Viability and Proliferation. Cell viability was assessed using MTT assay. A total of $24 \mathrm{~h}$ after seeding, hMSCs on the nanofibers at a density of $5 \times 10^{3}$ cells $\mathrm{cm}^{-1}$, cells were treated with (3-(4,5dimethylthiazol-2-yl)-2,5-diphenyltetrazolium bromide (MTT) reagent (Sigma-Aldrich). Following a $3 \mathrm{~h}$ postincubation period, the optical density of the purple color, as indicative of the number of live cells, was quantified at $590 \mathrm{~nm}$. Proliferative cells were determined using Click-iT EdU assay (Molecular Probes). hMSCs were incubated with a nucleoside analogue of thymine, EdU (5-ethynyl-20deoxyuridine), in the culture media. EdU incorporates in DNA during the synthesis phase ( $\mathrm{S}$ phase) of the cell cycle, and hence enables direct quantification of proliferation. hMSCs were seeded on the substrates at a density of $2.5 \times 10^{3} \mathrm{cells} \mathrm{cm}^{-1}$. Following the initial $8 \mathrm{~h}$ incubation after seeding, the medium was replaced with $10 \mathrm{mM}$ EdUcontaining fresh media supplemented with $20 \%$ FBS. Cells were postincubated for 1,3 , and 5 days. Cells were then fixed with $4 \%$ formaldehyde, permeabilized with $5 \%$ Triton- $\mathrm{X}$, and treated with Alexaflour-488 conjugated azide as recommended by the supplier. Proliferative cells were quantified by fluorescent microscope. The average counts of stained cell nuclei were used to evaluate the relative proliferative cell numbers. Both viability and proliferation results were normalized to that of bare titanium on day 1 .

Osteogenic Differentiation of hMSC. Osteogenic stimulatory media containing xeno-free serum was obtained from MesenCult (Catalog \#05434), which was formulated for the in vitro differentiation of hMSCs into osteogenic progenitor cells. hMSCs were grown until reaching $100 \%$ confluency. Then, FBS-containing medium was replaced with fresh MesenCult medium supplemented with $1 \%$ penicillin/streptomycin and $3.5 \mathrm{mM} \beta$-glycerophosphate. The differentiation medium was changed every 3-4 days for up to 28 days.

Alkaline Phosphatase Activity. Alkaline phosphatase activity of the cell extracts cultured on the modified surfaces was assessed by spectrophotometrically monitoring formation of the cleavage product, 4-nitrophenol, from 4-nitrophenyl phosphate (Sigma-Aldrich). Total protein from the cultured cells was extracted by $95 \%$ M-PER protein extraction kit (Thermo) with $5 \%$ protease inhibitor cocktail (Thermo). The enzymatic activities were normalized to the total protein content, which was determined by BCA protein assay kit (Pierce). The enzymatic activity was probed before (day 0 ) and after (days 3, 7, 14, 21, and 28) osteogenic induction.

Alizarin Red Staining. To detect calcium deposited by the cells, the substrates were stained with Alizarin red-S before (day 0 ) and after (days 7, 14, 21, and 28) osteogenic induction. First, the cells seeded on the substrates were fixed with ice-cold ethanol for $1 \mathrm{~h}$. Then, the substrates were treated with $40 \mathrm{nM}$ Alizarin red-S solution ( $\mathrm{pH} 4.2$ ) for $30 \mathrm{~min}$, followed by thorough washing with water. To quantify the amount of calcium, Alizarin-red-bound-calcium was extracted using 10 wt $\%$ cetylpyridinium chloride in $10 \mathrm{mM}$ sodium phosphate ( $\mathrm{pH} 7.0$ ) for $20 \mathrm{~min}$ at room temperature. The concentration of calcium was indirectly determined by measuring the optical density at $562 \mathrm{~nm}$.

Quantitative Reverse Transcription Polymerase Chain Reaction (qRT-PCR). Gene expression profiles for osteogenic differentiation (RUNX2 and COL1A1) were assessed by quantitative reverse transcription polymerase chain reaction. Total RNA was isolated from the differentiated cells on day 28 using TRIzol (Ambion) according to the manufacturer's instructions. Yield and purity of the extracted RNA were quantified by Nanodrop 2000 from Thermo Scientific. Primer sequences were designed using Primer 3 software (Table S2). SuperScript III Platinum SYBR Green One-Step qRTPCR kit was used to carry out cDNA synthesis from RNA and qPCR sequentially within the same reaction tube. Temperature cycling for 


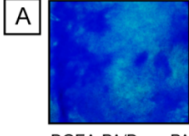

DGEA-PA/Dopa-PA

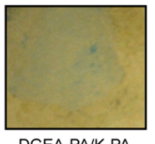

DGEA-PA/K-PA

$B$

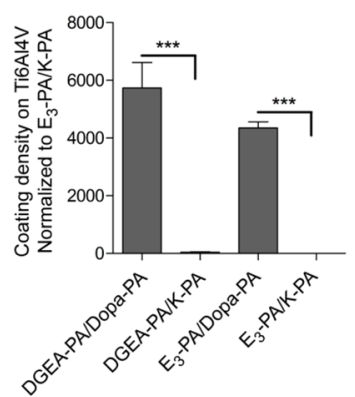

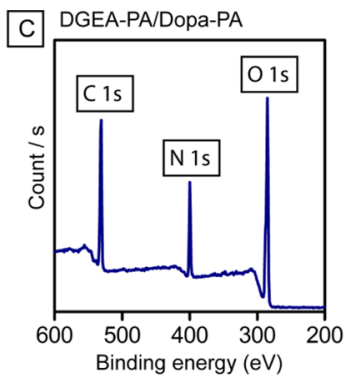

DGEA-PA/K-PA

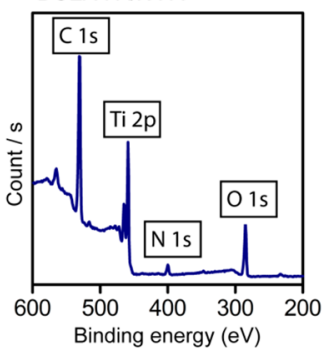

$E_{3}$-PA/Dopa-PA

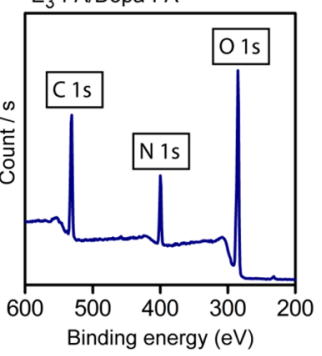

$E_{3}-\mathrm{PA} / \mathrm{K}-\mathrm{PA}$

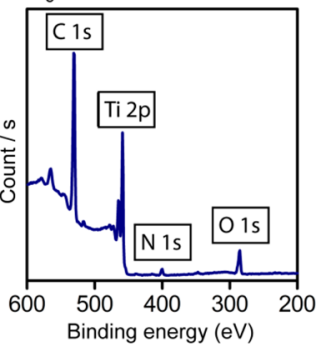

Figure 2. Dopa imparts surface stability to osteoinductive nanofibers. (A) Coomassie Blue staining shows the surface-bound peptide nanofibers. Coatings remained on Ti6Al4V substrates after washing sequentially in 10× PBS and $10 \mathrm{wt} \%$ SDS. (B) Digitalized spot density of the staining where the results were normalized to the spot density of $\mathrm{E}_{3}$-PA/K-PA. (C) X-ray photoelectron spectra of the coatings after the washing procedure $(* * * P$ $<0.0001)$.

the overall reaction was as follows: $55^{\circ} \mathrm{C}$ for $5 \mathrm{~min}, 95^{\circ} \mathrm{C}$ for $5 \mathrm{~min}$, 40 cycles of $95^{\circ} \mathrm{C}$ for $15 \mathrm{~s}, T_{\mathrm{m}}\left(58.3,60.0\right.$, and $58.0^{\circ} \mathrm{C}$ for RUNX2, COL1A1, and GAPDH, respectively) for $30 \mathrm{~s}$, and $40{ }^{\circ} \mathrm{C}$ for $1 \mathrm{~min}$, which was followed by a melting curve analysis. The reaction efficiency for each primer set was determined by a standard curve with 2 -fold serial dilutions of the total RNA. Gene expressions were normalized to that of GAPDH, which served as the internal control gene. A comparative $C_{\mathrm{t}}$ method was used to analyze the results.

Immunofluorescence and DMP-1 Localization. Differentiated cells (day 28) were first fixed with $4 \%$ formaldehyde for $15 \mathrm{~min}$ and then permeabilized with $0.5 \%$ Triton-X for $10 \mathrm{~min}$ at room temperative. For blocking, 3 wt \% BSA/PBS was applied for $1 \mathrm{~h}$. Rabbit-raised, antihuman, DMP-1 polyclonal primary and a goatraised, antirabbit, IgG H\&L DyLight 488 conjugated secondary antibodies (ab82351 and ab96899, respectively) were obtained from Abcam. Filamentous actins were stained with TRITC-conjugated phalloidin and the cell nuclei were stained with TO-PRO-3 iodide. The samples were analyzed with a Zeiss LSM 510 confocal microscope. DMP-1 localization was quantified based on the cellular images acquired in randomized areas at each group. In each group, a min of 80 and a max of 210 cells were analyzed. Each cell was investigated to observe whether DMP-1 expression was positive, and if so, whether it is predominantly nuclear, predominantly cytoplasmic, nuclear and cytoplasmic, or extracellular matrix positive.

Statistical Analysis. All experiments were independently repeated at least twice, with at least four replica for each experimental or control group in each independent assay. All quantitative results are expressed as mean \pm standard error of means (s.e.m.). Statistical analyses were carried out by one-way analysis of variance (ANOVA) or Student's $t$ test, whichever applicable. A $P$-value of less than 0.05 was considered statistically significant.

\section{RESULTS AND DISCUSSION}

Design of the Building Blocks and Self-Assembly into Multifunctional Nanofibers. DGEA-PA and $\mathrm{E}_{3}$-PA were designed to have net charges of -3 , while Dopa-PA and K-PA had a +1 net charge at $\mathrm{pH} 7.4$ (Figure 1A, Table S1). Mixing oppositely charged DGEA-PA (or $\mathrm{E}_{3}-\mathrm{PA}$ ) with Dopa-PA (or K$\mathrm{PA})$ at 1:3 molar ratios drove the self-assembly into high- aspect-ratio nanofibers (Table 1, Figure 1B).$^{41}$ Modular parts of PAs concertedly act in the process of self-assembly, as previously reported in detail. ${ }^{31,41}$ Briefly, hydrophobic collapse and van der Waals interactions at the hydrophobic module are accompanied by one-dimensional fibrillation through hydrogen bonding in the direction of fiber elongation..$^{11,42}$ Buried hydrophobic domains inside the nanofibers result in a micellar structure, which allows for well-defined and high-density presentation of the functional moieties to the outer aqueous environment. Molecular presentation density of DGEA and $\mathrm{E}_{3}$ were the same in all nanofiber combinations (Table 1). K-PA contained the same amino acid sequence of Dopa-PA, except for the Dopa residue, thereby serving as the control of the Dopa functionality. Densely interconnected nanofibers culminate in the formation of nanonetworks at a size scale similar to a native extracellular matrix (Figure 1B, Figure S2a). ${ }^{31,43,44} \beta$ Sheet-like organization was evident in all of the nanofiber constructs, as demonstrated by circular dichroism (Figures 1C and S2B). When individual PAs are dissolved in water, their $\beta$ sheet forming capacity is limited as assessed from the magnitude of molar ellipticity. However, their combined capacity of $\beta$-sheet formation after mixing becomes much greater than the sum of the individual fibers. This showed emerging electrostatic interaction between the oppositely charged PA molecules stabilizes PAs to drive nanofiber formation. ${ }^{42}$ Zeta potential measurements further supported the formation of self-assembly process, as mixing two oppositely charged PA molecules reduced the stability of the individual solutions, dropping in between $\pm 30 \mathrm{mV}$, indicating aggregations due to self-assembly at $\mathrm{pH} 7.4$ (Figures $1 \mathrm{D}$ and S2C).

Surface Stability of the Nanofibrous Peptide Coatings. As the model surface, Ti6Al4V is abundantly used as orthopedic and dental support for its comparatively lower weight and corrosion properties, Dopa-mediated stability of the nanofibers on titanium (Ti6Al4V) surface was investigated 


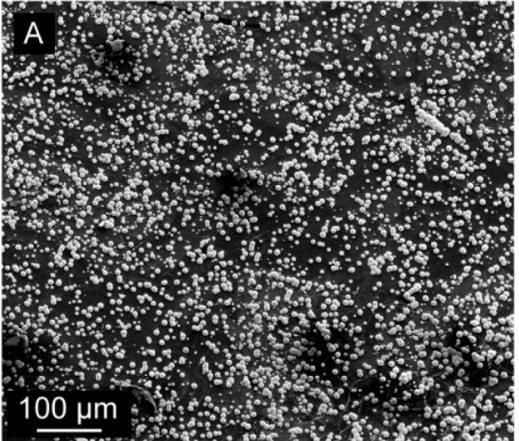

DGEA-PA/Dopa-PA, 3 days in SBF

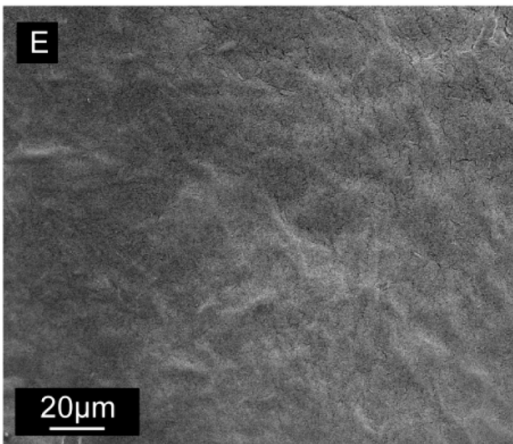

DGEA-PA/K-PA, 9 days in SBF

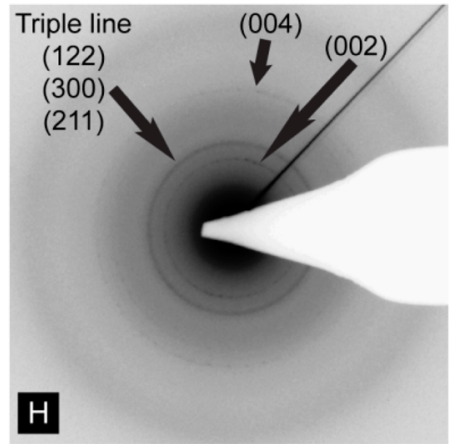

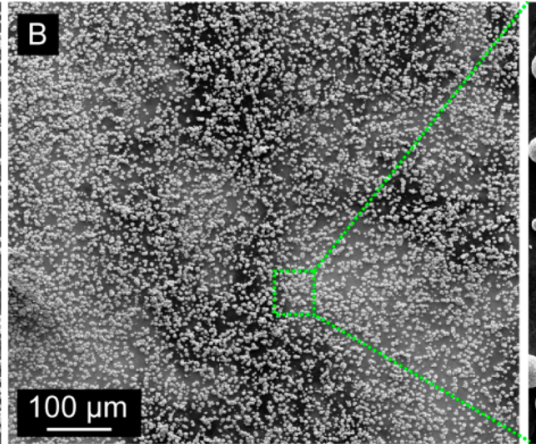

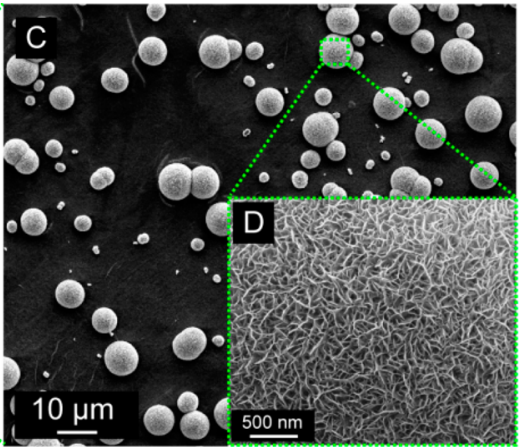

$E_{3}-P A / D o p a-P A, 3$ days in SBF

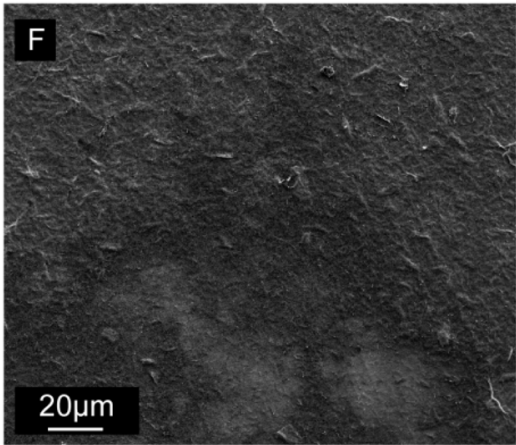

$E_{3}-P A / K-P A, 9$ days in SBF

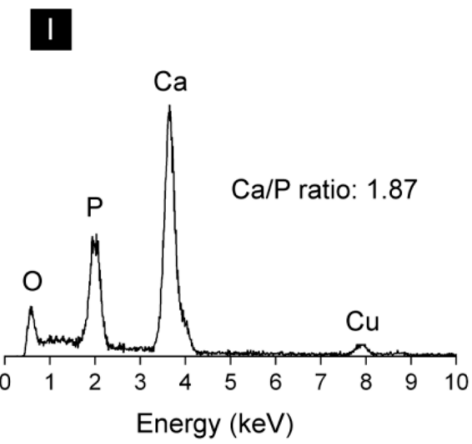

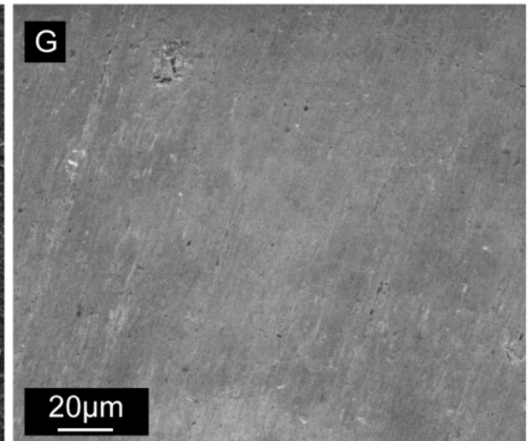

Bare Ti6Al4V, 9 days in SBF
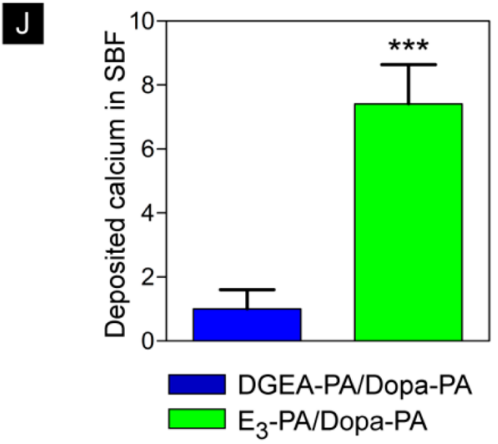

Figure 3. Hydroxyapatite formation on PA nanofibers in simulated body fluid. (A, B) SEM micrographs of DGEA-PA/Dopa-PA and E 3 -PA/DopaPA coated titanium surfaces on day 3. Hydroxyapatite islands nucleate from the surface of nanofibers, forming lath-like porous crystals (C, D). Dopa residue has a predominant role in hydroxyapatite formation, as evidenced by the absence of the mineralization on DGEA-PA/K-PA and $\mathrm{E}_{3}$-PA/K-PA up to 9 days in SBF (E, F). Bare titanium also did not trigger mineralization (G). (H, I) Diffraction patterns in SAED and Ca/P ratio in EDS identify the deposited mineral as hydroxyapatite. (J) On $\mathrm{E}_{3}$-PA/Dopa-PA nanofibers, glutamic acid residues synergize with Dopa, leading to significantly higher amount (fold difference) of hydroxyapatite formation compared to DGEA-PA/Dopa-PA (day 3 ; *** $P<0.0001$ ).

against harsh chemical washing. Washing in a solution with high ionic strength (10× PBS), followed by surfactant treatment ( $10 \mathrm{wt} \%$ sodium dodecyl sulfate) under mechanical shearing creates a daunting environment where loosely attached ligands would be easily displaced. As a result, DGEA-PA/K-PA and $\mathrm{E}_{3}-\mathrm{PA} / \mathrm{K}-\mathrm{PA}$ nanofibers were almost completely washed away after the treatment (Figure 2A). In sharp contrast, DGEA$\mathrm{PA} /$ Dopa-PA and $\mathrm{E}_{3}-\mathrm{PA} /$ Dopa-PA nanofibers remained on the titanium surface. This suggests DGEA-PA/Dopa-PA and $\mathrm{E}_{3}$ PA/Dopa-PA nanofibers permanently, that is, covalently, bonded to the titanium surface, which could be attributed to the interaction of Dopa with the surface. Digitalized quantity of the coomassie dye, following a standard destaining protocol, showed that the density of Dopa-containing nanofibers were in excess of $4 \times 10^{3}$-fold higher compared to DGEA-PA/K-PA and $\mathrm{E}_{3}-\mathrm{PA} / \mathrm{K}-\mathrm{PA}$ (Figure $2 \mathrm{~B}$ ). Dense surface coverage of DGEA-PA/Dopa-PA and $\mathrm{E}_{3}$-PA/Dopa-PA nanofibers on a titanium surface was further vindicated by $\mathrm{X}$-ray photoelectron spectroscopy (XPS). Complete suppression of the titanium photoelectron signal with the appearance of intense nitrogen signals was indicative of the peptide bound to the surface (Figure 2C). However, the presence of the titanium signal in addition to the much weaker nitrogen signal suggested removal of the large portion of the coating during the washing step. Altogether, Dopa residue on the nanofibers enabled robust surface biofunctionalization, which is essential for better restorative capacity and enhancing the biocompatibility of the underlying biomaterial.

Surface Mineralization with Biological Apatite. A material that supports growth of bone-like HAp is considered bioactive and, hence, has the capacity for bone bonding. SBF contains most of the ionic components of the blood plasma at comparable concentrations in an artificially prepared solution. ${ }^{45}$ When the titanium substrates functionalized with DGEA-PA/ Dopa-PA and $\mathrm{E}_{3}-\mathrm{PA} /$ Dopa-PA nanofibers were transferred to SBF, the surfaces were found to be densely covered with 

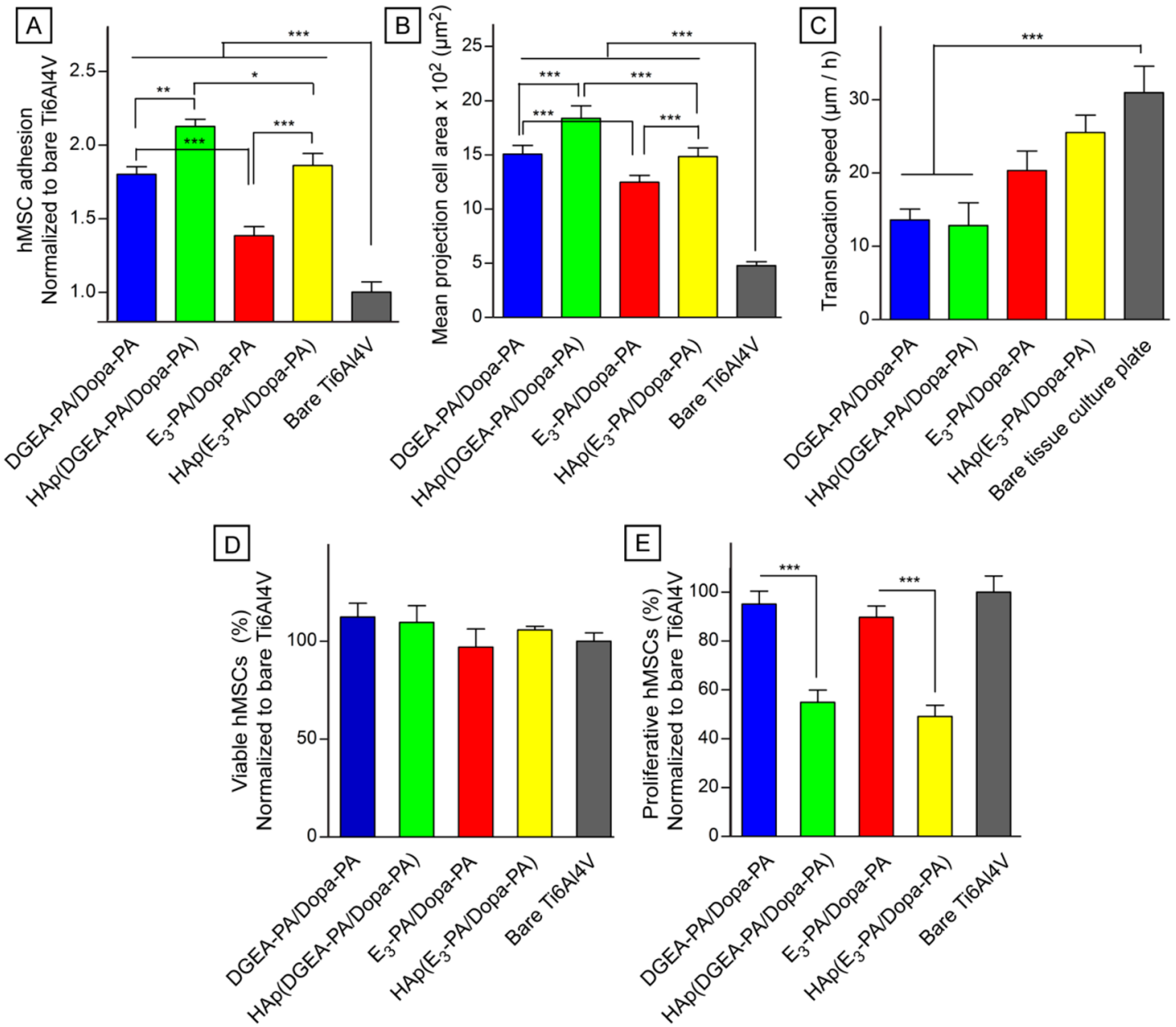

Figure 4. Early stage interactions of hMSCs with the osteoinductive nanofibers. (A, B) Adhesion and spreading of hMSCs on the nanofiber coatings in serum-free medium at $2 \mathrm{~h} 15 \mathrm{~min}$. (C) Translocation speed of hMSCs. (D) Viability of hMSCs at $24 \mathrm{~h}$. (E) Proliferative hMSCs over the course of 5 days $(* P<0.05, * * P<0.01, * * * P<0.0001, \Delta P<0.0001$; comparing day 1 with both day 3 and day 5$)$.

spherical calcium phosphate minerals (Figure $3 \mathrm{~A}-\mathrm{C}$ ). Detailed investigation showed that these minerals began to form within 6-12 $\mathrm{h}$ and become microscopically detectable after $24 \mathrm{~h}$ of incubation (Figure S3). As the incubation time increases, both the mineral density on the surface increases and the individual island sizes get bigger (Figure S3A). SAED and XRD patterns confirmed the minerals as HAp (Figures $3 \mathrm{H}$ and S4C). ${ }^{31,46,47}$ EDS showed the overwhelming presence of calcium and phosphorus in the minerals. $\mathrm{Ca} / \mathrm{P}$ molar ratio was found to be 1.87, a close value to that of HAp (1.67; Figure 3I). ${ }^{48}$ Higher magnification SEM and TEM analyses showed characteristic flakes of HAp that form porous structure on the mineral islands (Figures 3D and S4A,B). Raman spectrum showed specific fingerprints of crystalline HAp was bone-mimetic carbonated apatite due to the carbonate peak located at $1070 \mathrm{~cm}^{-1}$ (Figure S4D). Microscopic analyses showed that HAp formation follows island growth (Volmer-Weber) mode, which due to a large number of surface nuclei generation followed by the growth of separate and uniform islands homogeneously distributed on the substrate (Figure S5). ${ }^{49}$ However, we did not observe any mineralization on the nanofiber constructs of DGEA-PA/K-PA and $\mathrm{E}_{3}$-PA/K-PA even after up to 9 days of treatment with SBF (Figures $3 \mathrm{E}, \mathrm{F}$ and S3). We also did not detect mineralization on bare Ti6Al4V (Figure 3G). These results highlight the indispensible role of Dopa residue for hydroxyapatite formation on surface. Ryu et al. reported that poly dopamine-coating assists HAp formation by $\mathrm{Ca}^{2+}$ binding of catechol groups. ${ }^{50}$ High negative charge density of oligo glutamic acid nanofibers can similarly induce hydroxyapatite formation in concentrated $\mathrm{CaCl}_{2}$ solution supplemented with $\beta$-glycerophosphate and alkaline phosphatase enzyme. ${ }^{51}$ On the other hand, analyzing mineralization in SBF is regarded as a more reliable strategy for understanding in vivo mineralization behavior of a biomaterial. ${ }^{45}$ Indeed, higher concentration of poly glutamic acid inhibits HAp formation through strongly binding to calcium ion, thereby inhibiting its supersaturation into the crystalline phase. ${ }^{52}$ Here, we combined the features of glutamic acid binding of calcium with that of catechol in the $\mathrm{E}_{3^{-}}$ PA/Dopa-PA nanofibers. By doing so, we obtained much higher $\mathrm{HAp}$ on $\mathrm{E}_{3}-\mathrm{PA} /$ Dopa-PA nanofibers compared to DGEA-PA/Dopa-PA in spite of the fact that both $\mathrm{E}_{3}-\mathrm{PA}$ and DGEA-PA possess the same net charge at $\mathrm{pH} 7.4$ (Figure 3J). Interestingly, SEM micrographs confirmed higher mineral density on $\mathrm{E}_{3}$-PA/Dopa-PA with smaller individual island size (Figure 3A,B). Due to locally higher negative charge density of $\mathrm{EEE}, \mathrm{E}_{3}-\mathrm{PA}$ has a superior Ca-sequestering capacity compared to DGEA-PA, which had somewhat alternating negative residues in its primary sequence. This was thought to cause formation of higher number of prenucleation clusters on $E_{3^{-}}$ PA/Dopa-PA nanofibers, followed by Dopa-mediated crystallization into HAp. ${ }^{53}$ Therefore, the bioactivity of $\mathrm{E}_{3}$-PA/Dopa- 

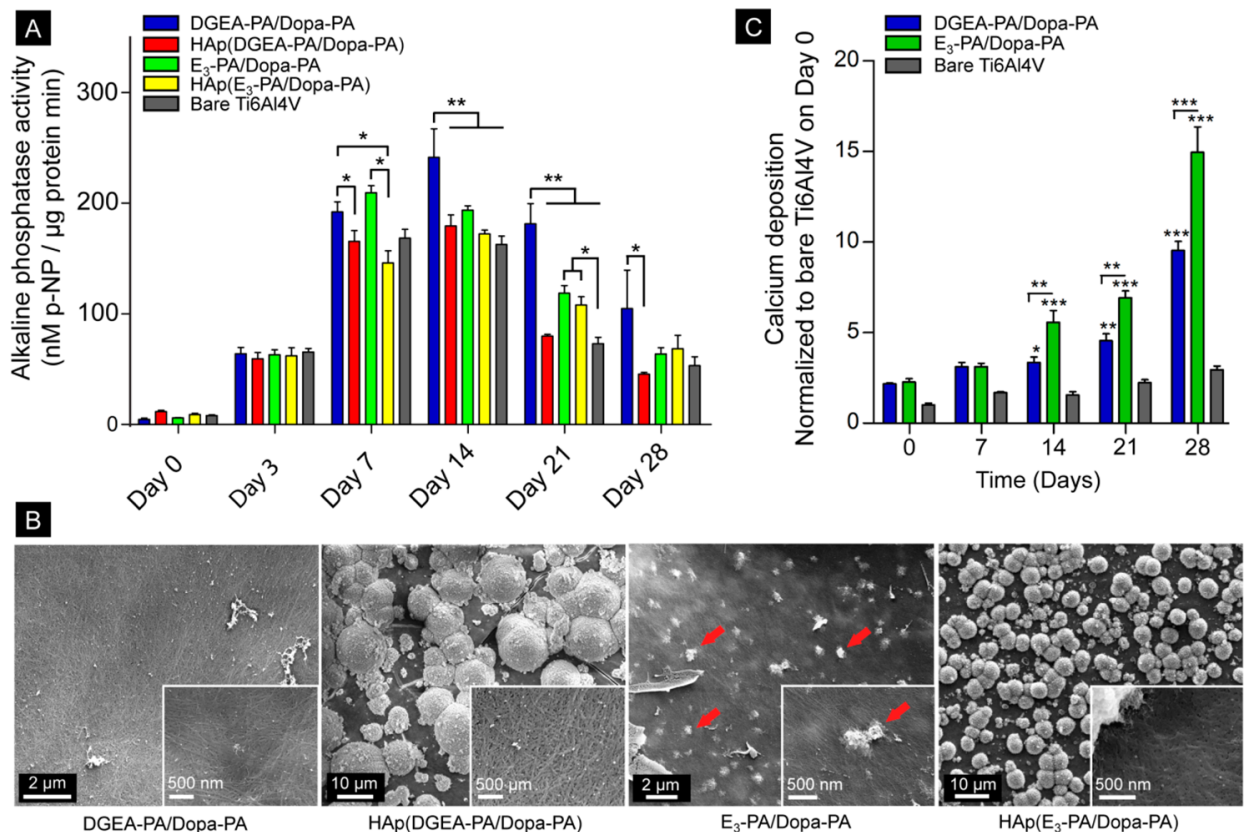

Figure 5. Osteoinductive effect of PA nanofibers on hMSCs. (A) Alkaline phosphatase activity of hMSCs over 4 weeks. (B) SEM micrographs of cell-seeded coatings, revealing the surface stability of the nanofibers against the cellular activity (day 28). Arrows point de novo calcium phosphate formation on $\mathrm{E}_{3}$-PA/Dopa-PA as a result of osteoblast activity. (C) Calcium deposition (fold difference) on the PA nanofibers over 4 weeks $(* P<$ $0.05, * * P<0.01, * * * P<0.0001)$.

PA for native bone integration was predicted to be higher than DGEA-PA/Dopa-PA.

Adhesion, Spreading, Migration, Survival, and Proliferation of hMSCs. A bioinstructive microenvironment for bone tissue regeneration should support adhesion, spreading, and survival of hMSCs and induce their differentiation into mineral-depositing osteoblasts. Adhesion and spreading are first prerequisite events for the survival, proliferation, and phenotypic behaviors of most of the cells that come into contact with a biomaterial. ${ }^{54-56}$ Moreover, analyses of these two parameters give direct evidence of specific cell-material contact. We investigated the adhesion and spreading of hMSCs on the nanofibers in serum-free medium supplemented with bovine serum albumin and cyclohexamide. Albumin acts to reduce nonspecific interactions with the nanofibers, whereby cyclohexamide inhibits the global translation process, which reduces the interference of endogenously synthesized proteins in the adhesion and spreading of the cells. By doing so, our emphasis was to enhance the signal pertaining to initial cellnanomaterial interactions. After $2 \mathrm{~h}$, the adhesion of hMSCs on DGEA-PA/Dopa-PA was found significantly higher than on $\mathrm{E}_{3}$ PA/Dopa-PA and bare Ti6Al4V (Figure 4A). Adhesion on HAp (DGEA-PA/Dopa-PA) was also higher than HAp ( $\mathrm{E}_{3}$ $\mathrm{PA} /$ Dopa-PA), revealing the significance of DGEA that facilitates direct contact between the cells and surface-bound nanofibers. This behavior is in agreement with the previous studies, in which DGEA ligand facilitates cell binding through its integrin $\alpha 2 \beta 1$ receptor. ${ }^{17}$ Interestingly, cell adhesion on both HAp (DGEA-PA/Dopa-PA) and HAp (E - PA/Dopa-PA) was higher compared to their nonmineralized counterparts. The enhanced total surface area on the mineralized substrates might be caused by the spherical HAp islands. Similar to the adhesion, the mean projection cell areas followed a trend, where hMSCs spread the most on the premineralized HAp (DGEA-PA/DopaPA) and DGEA-PA/Dopa-PA coatings (Figure 4B). To further support this specific interaction, we investigated the cell motility of hMSCs on the nanofibers. Previously it was shown that cell motility and adhesion strength often show opposite trends. ${ }^{56-58}$ This can allow empirical evaluation of the interaction between hMSCs and the nanofibers, such that cells should be slowest on the DGEA-presenting nanofibers as the interaction strength between DGEA ligands on the nanofibers and the surface receptors slows the overall cell motility. Indeed, on both DGEA-PA/Dopa-PA and HAp (DGEA-PA/Dopa-PA) coatings, cell locomotion was significantly slower than on bare surface (Figure 4C). In addition to these early stage cell-matrix interactions, the nanofibers were also found to be biocompatible as evaluated by the comparable viability levels at $24 \mathrm{~h}$ (Figure 4D). Furthermore, hMSCs continued proliferation at comparable levels on DGEA-PA/Dopa-PA and $\mathrm{E}_{3}$-PA/Dopa$\mathrm{PA}$. On the other hand, the proliferative cell numbers significantly decreased on the premineralized coatings (Figure $4 \mathrm{E}$ ). This could be due to the commitment of hMSCs for differentiation on the mineralized HAp (DGEA-PA/Dopa-PA) and HAp (E $-\mathrm{PA} /$ Dopa-PA) surfaces. Similar to our observation, adipose-derived mesenchymal stem cell proliferation was previously reported to be negatively correlated with the mineral content on a nanofibrous polymer scaffold. ${ }^{59}$

Osteogenic Differentiation of hMSCs. Differentiation of hMSCs along the osteoblast lineage begins with commitment to osteoprogenitor cells followed by differentiation into preosteoblasts and finally maturation into functional osteoblasts. A biochemical marker for the initial commitment to osteoprogenitor cells is the elevated alkaline phosphatase (ALP) activity, which is a prerequisite for enriching bone formation site with inorganic phosphates. Over the course of 3 weeks, hMSCs cultured on DGEA-PA/Dopa-PA nanofibers exhibited the highest ALP activity after day 7 (Figure 5A). This was attributable to the initial osteoinductive signal provided by the DGEA sequence. This result is also in agreement with a previous study where DGEA ligand presented on a nanofibrous phage induced early differentiation of mouse preosteoblasts. ${ }^{10}$ 

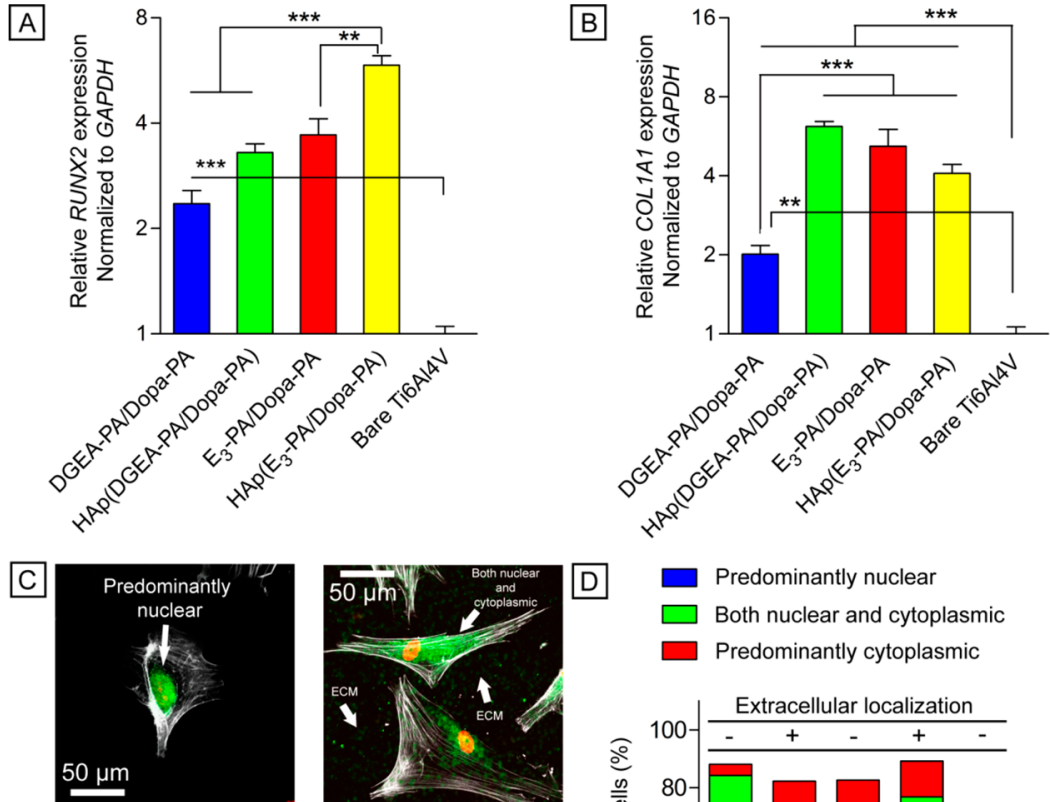

DGEA-PA/Dopa-PA
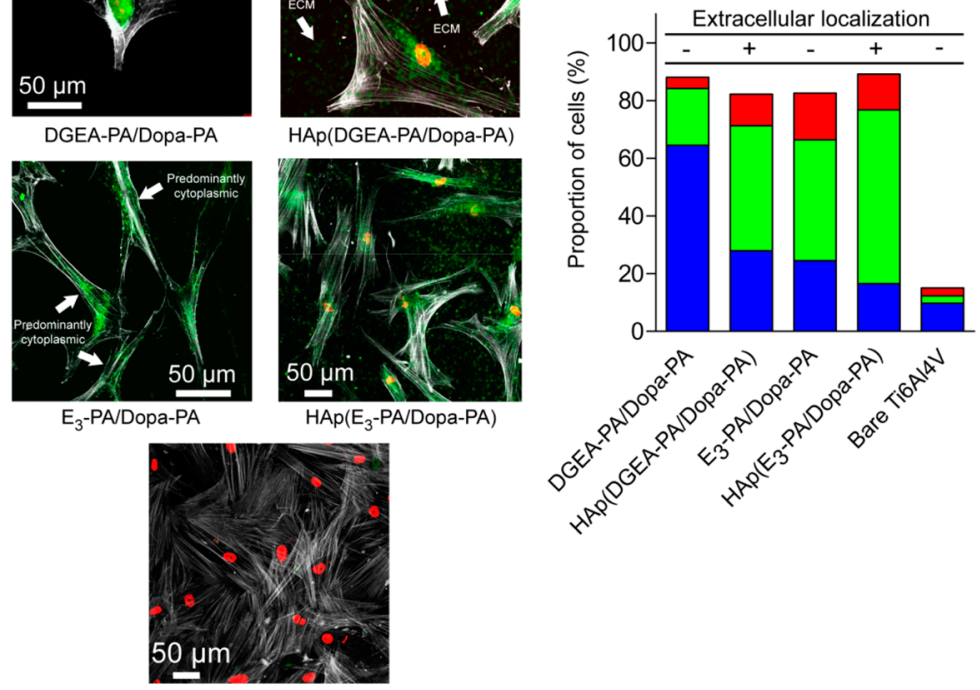

$\mathrm{HAp}\left(\mathrm{E}_{3}-\mathrm{PA} / \mathrm{Dopa}-\mathrm{PA}\right)$

Bare Ti6Al4V

Figure 6. Differentiation of hMSCs into the osteoblast lineage cells by PA nanofibers. (A, B) Expression levels of RUNX2 and COL1A1 genes confirm the osteogenic differentiation by day 28. Localization of DMP-1 protein inside the cell is informative about the differentiation stage of the cell within the osteoblast linage. (C) Confocal images of DMP-1 immunostaining. The arrows point the nuclear, cytoplasmic, or extracellular localization of DMP-1. Green shows DMP-1, gray shows filamentous actin, red shows the nucleus. (D) Distribution of DMP-1 localization in cell populations $(* * P<0.01, * * * P<0.0001)$.

Interestingly, ALP activities stimulated by premineralized HAp (DGEA-PA/Dopa-PA) and HAp (E-PA/Dopa-PA) nanofibers tended to remain lower (since day 7 , up to day 21 ) than their nonmineralized nanofiber counterparts. On both nanofiber systems, typical spindle-like morphology of hMSCs completely differentiated to osteoblast-like large cells over 28 days of differentiation (Figure S6). Some cells also contained multiple protrusions, with smaller cell body, reminiscent of osteocyte precursors. SEM micrographs of the surfaces acquired on day 28 confirmed the stability of the coatings against the biochemical activity of the cells, showing that osteoinductive signals of the nanofibers were be sustained over the course of the experiment (Figure 5B).

Notably, on the $\mathrm{E}_{3}$-PA/Dopa-PA nanofibers, we observed de novo agglomerates of calcium phosphate, which were attributed to the activity of mature osteoblasts (Figures 5B and S7A). Since the alkaline phosphatase activity was higher on DGEAPA/Dopa-PA, the resulting mineralization was expected to be higher as well. However, we did not observe similar aggregates on DGEA-PA/Dopa-PA coatings. It is also important to highlight that the flakes of HAp islands on HAp (DGEA-PA/ Dopa-PA) and HAp ( $\mathrm{E}_{3}$-PA/Dopa-PA) got thickened after 28 days in culture with cells (Figure S7B). This was attributed to the activity of differentiated cells, so that de novo calcium phosphate continued to grow over the existing mineral. Nevertheless, newly nucleated calcium phosphate aggregates were also evident (Figure S7C).

To further analyze the osteoinductive effect of DGEA-PA/ Dopa-PA and $\mathrm{E}_{3}-\mathrm{PA} /$ Dopa-PA on the osteogenic differentiation of hMSCs, we quantified deposited calcium as a result of cellular bioactivity of the maturated osteoblasts. We deduce that day 14 marks the emergence of mature osteoblasts, which is signified by the significantly higher amount of deposited calcium on both DGEA-PA/Dopa-PA and $\mathrm{E}_{3}-\mathrm{PA} /$ Dopa-PA nanofibers in comparison with the bare titanium (Figure 5C). On day 14, the amount of calcium deposited on $\mathrm{E}_{3}$-PA/Dopa-PA was also significantly higher than that of DGEA-PA/Dopa-PA. This difference continued to increase until day 28. Even though initial ALP activity was higher by the induction of DGEA-PA/Dopa-PA, $\mathrm{E}_{3}$-PA/Dopa-PA induced 
mature osteoblast formation more efficiently. Taking into account Figure 3J, where HAp deposition on $\mathrm{E}_{3}$-PA/Dopa-PA was greatly increased as a result of the synergistic interaction of polyglutamic acid groups with Dopa; we accounted this mainly to more favorable chemical properties of $\mathrm{E}_{3}-\mathrm{PA} / \mathrm{Dopa}-\mathrm{PA}$, which could better facilitate the mineralization by cellular activity. As a result, the overall mineral formation on the $\mathrm{E}_{3}$ PA/Dopa-PA rapidly increased compared to DGEA-PA/DopaPA.

To assess the impact of accelerated mineralization by $\mathrm{E}_{3}-\mathrm{PA} /$ Dopa-PA on the differentiation of hMSCs, we explored the expression of genes associated with osteoblastogenesis. Runtrelated transcription factor 2 (RUNX2) and collagen type I alpha 1 (COL1A1) are two cardinal marker proteins of this process, so their expression levels is informative about the differentiation stage of the cells. Here, we also included premineralized HAp (DGEA-PA/Dopa-PA) and HAp ( $\mathrm{E}_{3}-\mathrm{PA}$ / Dopa-PA) compositions to better evaluate the impact of mineralization on the differentiation in comparison with their nonmineralized nanofibers. On day 28, the highest RUNX2 gene expression was observed on HAp ( $\left.\mathrm{E}_{3}-\mathrm{PA} / \mathrm{Dopa}-\mathrm{PA}\right)$ and the lowest on the bare titanium (Figure 6A). Although statistically not significant, the expression of RUNX2 on HAp (DGEA-PA/Dopa-PA) was found higher than that of DGEAPA/Dopa-PA. A similar trend was also observed in the expression of COL1A1 gene where the expression levels were comparable among HAp (DGEA-PA/Dopa-PA), HAp (E E $_{3}-\mathrm{PA} /$ Dopa-PA), and $\mathrm{E}_{3}-\mathrm{PA} /$ Dopa-PA (Figure 6B). However, the lower expressions of COL1A1 and RUNX2 on DGEA-PA/ Dopa-PA compared to the other coatings show that maturation of cells was at a lesser stage on DGEA-PA/Dopa-PA. To further confirm this result, we investigated the intracellular and extracellular localization of dentin matrix protein-1 (DMP-1). DMP-1 belongs to the Small Integrin Binding Ligand N-Linked glycoprotein family (SIBLINGs) expressed in osteoblasts and osteocytes. ${ }^{60}$ DMP-1 can be found in the nucleus, cytoplasm, or extracellular matrix, depending on the maturation state of osteoblasts. ${ }^{61}$ This protein has a dual role in the biomineralization process. In preosteoblasts, DMP-1 is predominantly localized in the nucleus where it acts as a transcriptional component for activation of osteoblast-specific genes, such as osteocalcin. $^{61}$ During the osteoblast maturation, phosphorylated DMP-1 is exported to the extracellular matrix where it regulates nucleation of hydroxyapatite. Therefore, localization of this protein is highly informative about the osteoinductivity of the nanofibers. On day 28, on DGEA-PA/Dopa-PA, more than $60 \%$ of the cells showed predominant nuclear localization, showing that more than half of the cells differentiated on these nanofibers were at the preosteoblast stage (Figure 6C). On the other hand, on all HAp (DGEA-PA/Dopa-PA), HAp ( $\mathrm{E}_{3}-\mathrm{PA}$ / Dopa-PA), and $\mathrm{E}_{3}-\mathrm{PA} /$ Dopa-PA coatings, predominant cytoplasmic localizations were evident. In addition, we observed extracellular localization of DMP-1, where phosphorylated DMP-1 proteins were attached to the HAp formed by the nanofibers on HAp (E $\mathrm{E}_{3}$-PA/Dopa-PA) and HAp (DGEA-PA/ Dopa-PA). ${ }^{62}$ As a result, we concluded that hMSC differentiation into mature osteoblasts was promoted in the highest degree by the premineralized compositions. Although we did not notice extracellular DMP-1 localization on $\mathrm{E}_{3}$-PA/Dopa$\mathrm{PA}$, its predominant localization in the cytoplasm shows that cells on these nanofibers were at a higher maturation stage compared to those on DGEA-PA/Dopa-PA. Conversely, even less than $20 \%$ of cells on the bare titanium showed positive
DMP-1 staining, indicating that differentiation efficiency was much lower compared to the osteoinduction of nanofiber systems. Altogether, these results show that even though early osteogenic commitment was enhanced on DGEA-PA/Dopa$\mathrm{PA}$, the maturation of cells into functional osteoblasts was more efficient on $\mathrm{E}_{3}$-PA/Dopa-PA, at almost comparable level to those of the premineralized peptide nanofibers.

\section{CONCLUSIONS}

In this study, we developed bioinspired multifunctional nanofibers, which served as osteoinductive interfaces between hMSCs and titanium surface. All PA nanofiber functionalized surfaces exhibited higher performance in terms of adhesion and differentiation of hMSCs, compared to uncoated titanium. We demonstrated that Dopa residue has two critical functions: mediating robust immobilization of the nanofibers onto titanium surface and nucleating bone-like hydroxyapatite minerals on the nanofibers. Although DGEA-PA/Dopa-PA mediates early adhesion and differentiation into osteoprogenitor cells, $\mathrm{E}_{3}-\mathrm{PA} /$ Dopa-PA efficiently directs mature osteoblast formation and subsequent mineralization. With that, we here showed that, on the contrary to the common thinking, ${ }^{10,13,63-66}$ an initial osteogenic commitment of the progenitor stem cells does not necessarily guarantee a priority for maturation into functional osteoblasts. Therefore, bone-like hydroxyapatite nucleating $\mathrm{E}_{3}-\mathrm{PA} / \mathrm{Dopa}-\mathrm{PA}$ nanofibers exhibit an outstanding induction of osteogenesis, which, we suggest, is owing to the physical proximity of Dopa and glutamic acid residues on the nanofibers, boosting hydroxyapatite formation. Overall, this synthetic platform is a successful example of effective employment of the reductionist approach for eliciting strong regenerative response through molecular level cellmaterial interactions.

\section{ASSOCIATED CONTENT}

\section{S Supporting Information}

LC-MS analysis of the peptides, further characterizations of their self-assembly, supporting analyses of bone-like apatite mineralization on nanofibers, cellular morphologies as a result of osteogenic differentiation, and hMSC surface marker characterizations. This material is available free of charge via the Internet at http://pubs.acs.org.

\section{AUTHOR INFORMATION}

\section{Corresponding Authors}

*E-mail: moguler@unam.bilkent.edu.tr.

*E-mail: atekinay@unam.bilkent.edu.tr.

\section{Notes}

The authors declare no competing financial interest.

\section{ACKNOWLEDGMENTS}

This project was supported by the Scientific and Technological Research Council of Turkey (TUBITAK) Grant Number 113M900. H.C. and S.K. express their gratitude for TUBITAKBIDEB fellowship. A.B.T. and M.O.G. acknowledge support from the Turkish Academy of Sciences Distinguished Young Scientist Award (TUBA-GEBIP). The authors thank Seher Ustun for her kind help in Alizarin red staining.

\section{REFERENCES}

(1) Gittens, R. A.; Olivares-Navarrete, R.; Schwartz, Z.; Boyan, B. D. Implant Osseointegration and the Role of Microroughness and 
Nanostructures: Lessons for Spine Implants. Acta Biomater. 2014, 10.1016/j.actbio.2014.03.037.

(2) Osborn, J. F.; Newesely, H. The Material Science of Calcium Phosphate Ceramics. Biomaterials 1980, 1 (2), 108-111.

(3) LeGeros, R. Z. Calcium Phosphate-Based Osteoinductive Materials. Chem. Rev. 2008, 108 (11), 4742-4753.

(4) Daculsi, G.; Passuti, N.; Martin, S.; Deudon, C.; Legeros, R. Z.; Raher, S. Macroporous Calcium Phosphate Ceramic for Long Bone Surgery in Humans and Dogs. Clinical and Histological Study. J. Biomed. Mater. Res. 1990, 24 (3), 379-396.

(5) Lavenus, S.; Louarn, G.; Layrolle, P. Nanotechnology and Dental Implants. Int. J. Biomater. 2010, 2010.

(6) Yuan, H.; Fernandes, H.; Habibovic, P.; de Boer, J.; Barradas, A. M. C.; de Ruiter, A.; Walsh, W. R.; van Blitterswijk, C. A.; de Bruijn, J. D. Osteoinductive Ceramics As a Synthetic Alternative to Autologous Bone Grafting. Proc. Natl. Acad. Sci. U.S.A. 2010, 107 (31), 1361413619.

(7) Alghamdi, H. S.; Bosco, R.; van den Beucken, J. J. J. P.; Walboomers, X. F.; Jansen, J. A. Osteogenicity of Titanium Implants Coated with Calcium Phosphate or Collagen Type-I in Osteoporotic Rats. Biomaterials 2013, 34 (15), 3747-3757.

(8) Dominici, M.; Le Mueller, I.; Slaper-Cortenbach, I.; Marini, F.; Krause, D.; Deans, R.; Keating, A.; Prockop, D.; Horwitz, E. Minimal Criteria for Defining Multipotent Mesenchymal Stromal Cells. The International Society for Cellular Therapy Position Statement. Cytotherapy 2006, 8 (4), 315-317.

(9) Pashuck, E. T.; Stevens, M. M. Designing Regenerative Biomaterial Therapies for the Clinic. Sci. Transl. Med. 2012, 4 (160), 160 sr4.

(10) Yoo, S. Y.; Kobayashi, M.; Lee, P. P.; Lee, S.-W. Early Osteogenic Differentiation of Mouse Preosteoblasts Induced by Collagen-Derived DGEA-Peptide on Nanofibrous Phage Tissue Matrices. Biomacromolecules 2011, 12 (4), 987-996.

(11) Mizuno, M.; Fujisawa, R.; Kuboki, Y. Type I Collagen-Induced Osteoblastic Differentiation of Bone-Marrow Cells Mediated by Collagen- $\alpha 2 \beta 1$ Integrin Interaction. J. Cell. Physiol. 2000, 184 (2), 207-213.

(12) Staatz, W. D.; Fok, K. F.; Zutter, M. M.; Adams, S. P.; Rodriguez, B. A.; Santoro, S. A. Identification of a Tetrapeptide Recognition Sequence for the $\alpha 2 \beta 1$ Integrin in Collagen. J. Biol. Chem. 1991, 266 (12), 7363-7367.

(13) Anderson, J. M.; Kushwaha, M.; Tambralli, A.; Bellis, S. L.; Camata, R. P.; Jun, H.-W. Osteogenic Differentiation of Human Mesenchymal Stem Cells Directed by Extracellular Matrix-Mimicking Ligands in a Biomimetic Self-Assembled Peptide Amphiphile Nanomatrix. Biomacromolecules 2009, 10 (10), 2935-2944.

(14) Hennessy, K. M.; Pollot, B. E.; Clem, W. C.; Phipps, M. C.; Sawyer, A. A.; Culpepper, B. K.; Bellis, S. L. The Effect of Collagen I Mimetic Peptides on Mesenchymal Stem Cell Adhesion and Differentiation, And on Bone Formation at Hydroxyapatite Surfaces. Biomaterials 2009, 30 (10), 1898-1909.

(15) Mizuno, M.; Kuboki, Y. Osteoblast-Related Gene Expression of Bone Marrow Cells during the Osteoblastic Differentiation Induced by Type I Collagen. J. Biochem. 2001, 129 (1), 133-138.

(16) Olivares-Navarrete, R.; Raz, P.; Zhao, G.; Chen, J.; Wieland, M.; Cochran, D. L.; Chaudhri, R. A.; Ornoy, A.; Boyan, B. D.; Schwartz, Z. Integrin $\alpha 2 \beta 1$ Plays a Critical Role in Osteoblast Response to MicronScale Surface Structure and Surface Energy of Titanium Substrates. Proc. Natl. Acad. Sci. U.S.A. 2008, 105 (41), 15767-15772.

(17) Popov, C.; Radic, T.; Haasters, F.; Prall, W. C.; Aszodi, A.; Gullberg, D.; Schieker, M.; Docheva, D. Integrins $\alpha 2 \beta 1$ and $\alpha 11 \beta 1$ Regulate the Survival of Mesenchymal Stem Cells on Collagen I. Cell Death Dis. 2011, 2, e186.

(18) Keselowsky, B. G.; Wang, L.; Schwartz, Z.; Garcia, A. J.; Boyan, B. D. Integrin $\alpha 5$ Controls Osteoblastic Proliferation and Differentiation Responses to Titanium Substrates Presenting Different Roughness Characteristics in a Roughness Independent Manner. J. Biomed. Mater. Sci., Part A 2007, 80 (3), 700-710.
(19) Layrolle, P. 1.112 - Calcium Phosphate Coatings. In Comprehensive Biomaterials; Paul, D., Ed. Elsevier: Oxford, 2011; pp 223-229.

(20) Shih, Y.-R. V.; Hwang, Y.; Phadke, A.; Kang, H.; Hwang, N. S.; Caro, E. J.; Nguyen, S.; Siu, M.; Theodorakis, E. A.; Gianneschi, N. C.; Vecchio, K. S.; Chien, S.; Lee, O. K.; Varghese, S. Calcium PhosphateBearing Matrices Induce Osteogenic Differentiation of Stem Cells through Adenosine Signaling. Proc. Natl. Acad. Sci. U.S.A. 2014, DOI: $10.1073 /$ pnas.1321717111.

(21) Tye, C. E.; Rattray, K. R.; Warner, K. J.; Gordon, J. A. R.; Sodek, J.; Hunter, G. K.; Goldberg, H. A. Delineation of the HydroxyapatiteNucleating Domains of Bone Sialoprotein. J. Biol. Chem. 2003, 278 (10), 7949-7955.

(22) Chien, C.-Y.; Tsai, W.-B. Poly(dopamine)-Assisted Immobilization of Arg-Gly-Asp Peptides, Hydroxyapatite, and Bone Morphogenic Protein-2 on Titanium to Improve the Osteogenesis of Bone Marrow Stem Cells. ACS Appl. Mater. Interfaces 2013, DOI: 10.1021/ am401071f.

(23) Lin, L.; Chow, K. L.; Leng, Y. Study of Hydroxyapatite Osteoinductivity with an Osteogenic Differentiation of Mesenchymal Stem Cells. J. Biomed. Mater. Res., Part A 2009, 89 (2), 326-335.

(24) Silva, G. A.; Czeisler, C.; Niece, K. L.; Beniash, E.; Harrington, D. A.; Kessler, J. A.; Stupp, S. I. Selective Differentiation of Neural Progenitor Cells by High-Epitope Density Nanofibers. Science 2004, 303 (5662), 1352-1355.

(25) Englund, E. A.; Wang, D.; Fujigaki, H.; Sakai, H.; Micklitsch, C. M.; Ghirlando, R.; Martin-Manso, G.; Pendrak, M. L.; Roberts, D. D.; Durell, S. R.; Appella, D. H. Programmable Multivalent Display of Receptor Ligands Using Peptide Nucleic Acid Nanoscaffolds. Nat. Commun. 2012, 3, 614.

(26) Ceylan, H.; Tekinay, A. B.; Guler, M. O. Selective Adhesion and Growth of Vascular Endothelial Cells on Bioactive Peptide Nanofiber Functionalized Stainless Steel Surface. Biomaterials 2011, 32 (34), $8797-8805$.

(27) Tejeda-Montes, E.; Smith, K. H.; Rebollo, E.; Gómez, R.; Alonso, M.; Rodriguez-Cabello, J. C.; Engel, E.; Mata, A. Bioactive Membranes for Bone Regeneration Applications: Effect of Physical and Biomolecular Signals on Mesenchymal Stem Cell Behavior. Acta Biomater. 2014, 10 (1), 134-141.

(28) Sargeant, T. D.; Rao, M. S.; Koh, C.-Y.; Stupp, S. I. Covalent Functionalization of NiTi Surfaces with Bioactive Peptide Amphiphile Nanofibers. Biomaterials 2008, 29 (8), 1085-1098.

(29) Mata, A.; Geng, Y.; Henrikson, K. J.; Aparicio, C.; Stock, S. R.; Satcher, R. L.; Stupp, S. I. Bone Regeneration Mediated by Biomimetic Mineralization of a Nanofiber Matrix. Biomaterials 2010, 31 (23), 6004-6012.

(30) Lim, Y.-b.; Moon, K.-S.; Lee, M. Recent Advances in Functional Supramolecular Nanostructures Assembled from Bioactive Building Blocks. Chem. Soc. Rev. 2009, 38 (4), 925-934.

(31) Hartgerink, J. D.; Beniash, E.; Stupp, S. I. Self-Assembly and Mineralization of Peptide-Amphiphile Nanofibers. Science 2001, 294 (5547), 1684-1688.

(32) Kocabey, S.; Ceylan, H.; Tekinay, A. B.; Guler, M. O. Glycosaminoglycan Mimetic Peptide Nanofibers Promote Mineralization by Osteogenic Cells. Acta Biomater. 2013, 9 (11), 9075-9085.

(33) Ustun, S.; Tombuloglu, A.; Kilinc, M.; Guler, M. O.; Tekinay, A. B. Growth and Differentiation of Prechondrogenic Cells on Bioactive Self-Assembled Peptide Nanofibers. Biomacromolecules 2012, 14 (1), $17-26$.

(34) Mammadov, B.; Mammadov, R.; Guler, M. O.; Tekinay, A. B. Cooperative Effect of Heparan Sulfate and Laminin Mimetic Peptide Nanofibers on the Promotion of Neurite Outgrowth. Acta Biomater. 2012, 8 (6), 2077-2086.

(35) Mammadov, R.; Mammadov, B.; Toksoz, S.; Aydin, B.; Yagci, R.; Tekinay, A. B.; Guler, M. O. Heparin Mimetic Peptide Nanofibers Promote Angiogenesis. Biomacromolecules 2011, 12 (10), 3508-3519.

(36) Ceylan, H.; Tekinay, A. B.; Guler, M. O. Mussel-Inspired Adhesive Interfaces for Biomedical Applications. In Biological and 
Biomimetic Adhesives: Challenges and Opportunities; The Royal Society of Chemistry: U.K., 2013; pp 103-116.

(37) Ceylan, H.; Kocabey, S.; Tekinay, A. B.; Guler, M. O. SurfaceAdhesive and Osteogenic Self-Assembled Peptide Nanofibers for Bioinspired Functionalization of Titanium Surfaces. Soft Matter 2012, 8 (14), 3929-3937.

(38) Meredith, H. J.; Jenkins, C. L.; Wilker, J. J. Enhancing the Adhesion of a Biomimetic Polymer Yields Performance Rivaling Commercial Glues. Adv. Funct. Mater. 2014, DOI: 10.1002/ adfm.201303536.

(39) Kang, S. M.; Hwang, N. S.; Yeom, J.; Park, S. Y.; Messersmith, P. B.; Choi, I. S.; Langer, R.; Anderson, D. G.; Lee, H. One-Step Multipurpose Surface Functionalization by Adhesive Catecholamine. Adv. Funct. Mater. 2012, 22 (14), 2949-2955.

(40) Penfornis, P.; Pochampally, R., Isolation and Expansion of Mesenchymal Stem Cells/Multipotential Stromal Cells from Human Bone Marrow. In Mesenchymal Stem Cell Assays and Applications, Vemuri, M.; Chase, L. G.; Rao, M. S., Eds. Humana Press: Totowa, NJ, 2011; Vol. 698, pp 11-21.

(41) Niece, K. L.; Hartgerink, J. D.; Donners, J. J. J. M.; Stupp, S. I. Self-Assembly Combining Two Bioactive Peptide-Amphiphile Molecules into Nanofibers by Electrostatic Attraction. J. Am. Chem. Soc. 2003, 125 (24), 7146-7147.

(42) Behanna, H. A.; Donners, J. J. J. M.; Gordon, A. C.; Stupp, S. I. Coassembly of Amphiphiles with Opposite Peptide Polarities into Nanofibers. J. Am. Chem. Soc. 2005, 127 (4), 1193-1200.

(43) Raspanti, M.; Protasoni, M.; Manelli, A.; Guizzardi, S.; Mantovani, V.; Sala, A. The Extracellular Matrix of the Human Aortic Wall: Ultrastructural Observations by FEG-SEM and by TappingMode AFM. Micron 2006, 37 (1), 81-86.

(44) Muthusubramaniam, L.; Peng, L.; Zaitseva, T.; Paukshto, M.; Martin, G. R.; Desai, T. A. Collagen Fibril Diameter and Alignment Promote the Quiescent Keratocyte Phenotype. J. Biomed. Mater. Res., Part A 2012, 100 (3), 613-621.

(45) Kokubo, T.; Takadama, H., Simulated Body Fluid (SBF) as a Standard Tool to Test the Bioactivity of Implants. In Handbook of Biomineralization; Wiley-VCH Verlag GmbH: New York, 2008; pp 97-109.

(46) Song, J.; Saiz, E.; Bertozzi, C. R. A New Approach to Mineralization of Biocompatible Hydrogel Scaffolds: An Efficient Process toward 3-Dimensional Bone-Like Composites. J. Am. Chem. Soc. 2003, 125 (5), 1236-1243.

(47) Spoerke, E. D.; Anthony, S. G.; Stupp, S. I. Enzyme Directed Templating of Artificial Bone Mineral. Adv. Mater. 2009, 21 (4), 425430.

(48) Ishikawa, K.; Ducheyne, P.; Radin, S. Determination of the Ca/ $P$ Ratio in Calcium-Deficient Hydroxyapatite Using X-ray Diffraction Analysis. J. Mater. Sci: Mater. Med. 1993, 4 (2), 165-168.

(49) Volmer, M. W. A. Keimbildung in Übersättigten Gebilden (Nucleation of supersaturated structures). Z. Phys. Chem. 1926, 119, 277-301.

(50) Ryu, J.; Ku, S. H.; Lee, H.; Park, C. B. Mussel-Inspired Polydopamine Coating as a Universal Route to Hydroxyapatite Crystallization. Adv. Funct. Mater. 2010, 20 (13), 2132-2139.

(51) Newcomb, C. J.; Bitton, R.; Velichko, Y. S.; Snead, M. L.; Stupp, S. I. The Role of Nanoscale Architecture in Supramolecular Templating of Biomimetic Hydroxyapatite Mineralization. Small 2012, 8 (14), 2195-2202.

(52) Li, L.; Mao, C.; Wang, J.; Xu, X.; Pan, H.; Deng, Y.; Gu, X.; Tang, R. Bio-Inspired Enamel Repair via Glu-Directed Assembly of Apatite Nanoparticles: an Approach to Biomaterials with Optimal Characteristics. Adv. Mater. 2011, 23 (40), 4695-4701.

(53) Dey, A.; Bomans, P. H. H.; Müller, F. A.; Will, J.; Frederik, P. M.; de With, G.; Sommerdijk, N. A. J. M. The Role of Prenucleation Clusters in Surface-Induced Calcium Phosphate Crystallization. Nat. Mater. 2010, 9 (12), 1010-1014.

(54) Schwartz, M. A.; Assoian, R. K. Integrins and Cell Proliferation: Regulation of Cyclin-Dependent Kinases via Cytoplasmic Signaling Pathways. J. Cell Sci. 2001, 114 (14), 2553-2560.
(55) Frisch, S. M.; Vuori, K.; Ruoslahti, E.; Chan-Hui, P. Y. Control of Adhesion-Dependent Cell Survival by Focal Adhesion Kinase. J. Cell Biol. 1996, 134 (3), 793-799.

(56) Mann, B. K.; West, J. L. Cell Adhesion Peptides Alter Smooth Muscle Cell Adhesion, Proliferation, Migration, And Matrix Protein Synthesis on Modified Surfaces and in Polymer Scaffolds. J. Biomed. Mater. Res. 2002, 60 (1), 86-93.

(57) Wilson, C. J.; Clegg, R. E.; Leavesley, D. I.; Pearcy, M. J. Mediation of Biomaterial-Cell Interactions by Adsorbed Proteins: A Review. Tissue Eng. 2005, 11 (1-2), 1-18.

(58) Sagnella, S. M.; Kligman, F.; Anderson, E. H.; King, J. E.; Murugesan, G.; Marchant, R. E.; Kottke-Marchant, K. Human Microvascular Endothelial Cell Growth and Migration on Biomimetic Surfactant Polymers. Biomaterials 2004, 25 (7-8), 1249-1259.

(59) Liu, W.; Lipner, J.; Xie, J.; Manning, C. N.; Thomopoulos, S.; Xia, Y. Nanofiber Scaffolds with Gradients in Mineral Content for Spatial Control of Osteogenesis. ACS Appl. Mater. Interfaces 2014, 6 (4), 2842-2849.

(60) D'Souza, R. N.; Cavender, A.; Sunavala, G.; Alvarez, J.; Ohshima, T.; Kulkarni, A. B.; MacDougall, M. Gene Expression Patterns of Murine Dentin Matrix Protein 1 (Dmp1) and Dentin Sialophosphoprotein (DSPP) Suggest Distinct Developmental Functions In Vivo. J. Bone Miner. Res. 1997, 12 (12), 2040-2049.

(61) Narayanan, K.; Ramachandran, A.; Hao, J.; He, G.; Park, K. W.; Cho, M.; George, A. Dual Functional Roles of Dentin Matrix Protein 1: Implications in Biomineralization and Gene Transcription by Activation of the Intracellular $\mathrm{Ca}^{2+}$ Store. J. Biol. Chem. 2003, 278 (19), 17500-17508.

(62) He, G.; Dahl, T.; Veis, A.; George, A. Nucleation of Apatite Crystals in Vitro by Self-Assembled Dentin Matrix Protein 1. Nat. Mater. 2003, 2 (8), 552-558.

(63) Anderson, J. M.; Vines, J. B.; Patterson, J. L.; Chen, H.; Javed, A.; Jun, H.-W. Osteogenic Differentiation of Human Mesenchymal Stem Cells Synergistically Enhanced by Biomimetic Peptide Amphiphiles Combined with Conditioned Medium. Acta Biomater. 2011, 7 (2), 675-682.

(64) You, M.-H.; Kwak, M. K.; Kim, D.-H.; Kim, K.; Levchenko, A.; Kim, D.-Y.; Suh, K.-Y. Synergistically Enhanced Osteogenic Differentiation of Human Mesenchymal Stem Cells by Culture on Nanostructured Surfaces with Induction Media. Biomacromolecules 2010, 11 (7), 1856-1862.

(65) Costa-Pinto, A. R.; Correlo, V. M.; Sol, P. C.; Bhattacharya, M.; Charbord, P.; Delorme, B.; Reis, R. L.; Neves, N. M. Osteogenic Differentiation of Human Bone Marrow Mesenchymal Stem Cells Seeded on Melt Based Chitosan Scaffolds for Bone Tissue Engineering Applications. Biomacromolecules 2009, 10 (8), 2067-2073.

(66) Liao, S.; Nguyen, L. T. H.; Ngiam, M.; Wang, C.; Cheng, Z.; Chan, C. K.; Ramakrishna, S. Biomimetic Nanocomposites to Control Osteogenic Differentiation of Human Mesenchymal Stem Cells. Adv. Health Mater. 2013, DOI: 10.1002/adhm.201300207. 